\title{
Treatment of community-acquired pneumonia: a randomized comparison of sparfloxacin, amoxycillin-clavulanic acid and erythromycin
}

\author{
H. Lode*, J. Garau**, C. Grassi', J. Hosie ${ }^{++}$, G. Huchon\#, N. Legakis"\#, \\ S. Segev $\$$, G. Wijnands $\$ \$$
}

Treatment of community-acquired pneumonia: a randomized comparison of sparfloxacin, amoxycillin-clavulanic acid and erythromycin. H. Lode, J. Garau, C. Grassi, J. Hosie, G. Huchon, N. Legakis, S. Segev, G. Wijnands. CERS Journals Ltd 1995.

ABSTRACT: The treatment of community-acquired pneumonia is empirical in most cases and must cover a wide range of potential pathogens, such as Streptococcus pneumoniae, including penicillin-resistant strains, Haemophilus influenzae and intracellular microorganisms.

The objective of this double-blind, randomized, parallel group study was to compare the efficacy and safety of sparfloxacin $(400 \mathrm{mg}$ loading dose, followed by $200 \mathrm{mg} \mathrm{o.d}$.) with that of oral amoxycillin-clavulanic acid $(500 / 125 \mathrm{mg}$ t.i.d.) or oral erythromycin ( $1 \mathrm{~g}$ b.i.d.), during 7-14 days in 808 patients with confirmed community-acquired pneumonia.

The overall success rates for sparfloxacin $(87 \%)$, amoxycillin-clavulanic acid $(80 \%)$ and erythromycin $(85 \%)$ were similar in evaluable patients, and the equivalence hypothesis used for the statistical analysis showed at least an equivalent efficacy for the three antibiotics tested. The analysis of microbiologically documented infections $(40 \%$ of the patients) showed that overall success rates were similar for $S$. pneumoniae and $\boldsymbol{H}$. influenzae infections. Treatment withdrawal was necessary in 3.5, 2.5 and $\mathbf{7 . 7 \%}$ of the patients treated with sparfloxacin, amoxycillin-clavulanic acid and erythromycin, respectively.

This study indicates that sparfloxacin was at least as effective as amoxycillinclavulanic acid or erythromycin in the treatment of mild-to-moderate communityacquired pneumonia and that the adverse effects were similar in the three groups. Eur Respir J., 1995, 8, 1999-2007.

\begin{abstract}
*Pneumology Dept I, Hospital Zehlendorf, Berlin, Germany. **Dept of Infectious Diseases, Hospital Mutua de Tarrasa, Tarrasa Spain. +Physiology Clinic and Respiratory Diseases Dept, San Matteo University Policlinic, Pavia, Italy. ${ }^{++}$Medical Practice, 1980 Great Western Road, Glasgow, UK. "Pneumology Dept, Hospital Ambroise Paré, Boulogne, France. "\#ational University of Athens, Dept of Microbiology, Athens, Greece. ${ }^{\text {s}}$ Chain Sheba Medical Center, Tel Hashomer, Israel. ${ }^{\$}$ Stichting Deventer Hospital, Deventer, Holland.
\end{abstract}

Correspondence: H. Lode, Hospital Zehlendorf, Pneumology Dept, Zum Heckeshorn 33, D-14109 Berlin, Germany

Keywords: Amoxycillin-clavulanic, community acquired pneumonia, erythromycin, sparfloxacin, treatment

Received: December 61994

Accepted after revision September 251995

The study was supported by a grant from Rhone D.P.C. Europe, 20 Av Raymond Aron, 92165 Antony, France.
Clinical trials of antibiotics generally aim to demonstrate the efficacy of a new antibiotic in comparison to older, reference antibiotics. However, as the advantage of new antibiotics is often fractional, their actual superiority is seldom shown in clinical trials on account of the limits imposed by the number of patients that can be realistically included, and an equivalence is generally concluded; this conclusion is not always statistically valid depending on the power of the test. It is necessary to compare secondary criteria, including microbiological data, in certain subpopulations to evaluate the therapeutic usefulness of a new antibiotic.

In addition, clinical studies in pneumonia may lack an adequate definition of the disease and differ from one study to another. Guidelines have been issued in the USA [1] and Europe, which recommend precise inclusion criteria, microbiological documentation and follow-up.

The classification of the outcome of antibiotic treatment of pneumonia is difficult, as it rests both on individual clinical and radiological (and sometimes microbiological and biological) outcomes. It is usually expressed in terms of cure, improvement, or failure. The classification of improvement is both subjective and inconsistent, and is variable from one study to another. Moreover, it does not represent the reality of medical use in an acute illness; and it prevents a true, binary expression of the outcome (cure or failure) used for the statistical analysis. Therefore, automatic rules of classification, into a success/failure category depending on clinical and radiological outcomes, would appear to be an interesting alternative.

Antibiotic treatment of community-acquired pneumonia (CAP), which is a medical emergency due to the potential severity of the disease, is empirical. Indirect clues can be obtained from the clinical and radiological signs and symptoms, the epidemiological context and the evidence of certain risk factors. No direct demonstration of the aetiological agent is sought, except in the case of previous antibiotic failure, or in the presence of signs of severity. Recommendations concerning first-line antibiotics have been issued by various professional bodies or authorities, in various countries in Europe [2, 3]. Amoxycillin is advocated in Europe as first-line antibacterial therapy in 
CAP. In the presence of a risk factor, such as chronic bronchitis, a combination of amoxycillin and clavulanic acid (alternatively an injectable cephalosporin in some countries) is preferred because it provides coverage against the majority of pathogens implicated. However, the prevalence of penicillin-resistant strains of Streptococcus pneumoniae or strains with reduced susceptibility to penicillin has been increasing, especially in Spain, France and several Eastern European countries [4]. The situation is further complicated by the increase in erythromycinresistant strains in recent years [4].

Atypical pathogens are not sensitive to $\beta$-lactam agents but are generally quite sensitive to macrolides. Therefore, erythromycin is recommended as alternative first-line treatment of CAP, if the clinical presentation suggests an atypical organism.

Sparfloxacin is a new derivative of pyridone carboxylic acid which, in vitro, has shown greater activity than currently marketed quinolones against the most common pathogens responsible for community-acquired respiratory tract infections. The minimal concentration of sparfloxacin causing 90\% inhibition (MIC90) against $S$. pneumoniae is $0.25 \mathrm{mg} \cdot \mathrm{L}^{-1}$ [5]. A peak serum concentration of $1.7 \mathrm{mg} \cdot \mathrm{L}^{-1}$ is reached after an oral $400 \mathrm{mg}$ loading dose of sparfloxacin, followed by a peak serum concentration of $1.4 \mathrm{mg} \cdot \mathrm{L}^{-1}$ after subsequent administration of $200 \mathrm{mg}$ daily. The elimination half-life of sparfloxacin is approximately $20 \mathrm{~h}$. Therefore, a loading dose of $400 \mathrm{mg}$ followed by $200 \mathrm{mg}$ once daily maintains plasma concentrations in excess of the MIC90 for S. pneumoniae for a full $24 \mathrm{~h}$. Honeybourne et al. [6] demonstrated that sparfloxacin concentrations in bronchial mucosal biopsies, epithelial lining fluid and alveolar macrophages were several to manyfold higher than plasma concentrations, and that high concentrations persisted for at least $24 \mathrm{~h}$ after oral administration of sparfloxacin.

As a result of these encouraging properties and preliminary findings, a study was designed to compare the clinical efficacy and safety of sparfloxacin and two reference antibiotics advocated for first-line use in Europe, amoxycillin-clavulanic acid or erythromycin in patients with CAP.

\section{Materials and methods}

\section{Study design and number of patients}

This was a double-blind, double-dummy, randomized, parallel group, multicentre, multinational, comparative clinical study involving 808 patients with confirmed nonsevere CAP, treated orally for 7-14 days with sparfloxacin (Rhone D.P.C. Europe, France), amoxycillin-clavulanate (SmithKline Beecham Laboratories, France) or erythromycin (August Wolff Laboratories, Germany) and followed for 6 weeks. Randomization was 2:1:1 to provide approximately equal numbers of patients in the sparfloxacin group and in the combined control groups. Blinding was accomplished with a triple placebo technique and patients were treated with sparfloxacin $(400 \mathrm{mg}$ loading dose followed by $200 \mathrm{mg}$ each morning), amoxycillinclavulanate $(500 / 125 \mathrm{mg}$ t.i.d), or erythromycin $(1,000 \mathrm{mg}$ b.i.d.). Patients were advised to avoid exposure to sunlight and tanning for the duration of treatment.

The number of patients was calculated using a hypothesis of equivalence of efficacy between sparfloxacin and amoxycillin-clavulanate and erythromycin. Estimating the success rate of both amoxycillin-clavulanate and erythromycin at $75 \%$, the detection of a maximum acceptable difference to $10 \%$ with a power of $80 \%$ and a risk of $5 \%$ required the inclusion of 270 evaluable patients in the sparfloxacin group and 135 in each of the amoxycillinclavulanatc and crythromycin groups. In order to make up for nonevaluability, a total of approximately 800 patients had to be enrolled.

\section{Patients}

Patients aged $\geq 18$ yrs with acute CAP were included in the study. Diagnosis was based on the presence of a new infiltrate (solid or patchy) on chest radiographic image, fever greater than $38^{\circ} \mathrm{C}$, and at least one of the typical clinical signs, including cough, dyspnoea, chills, sputum production and/or chest pain, or a white blood cells (WBC) count of 10,000-30,000 cells $\mu \mathrm{L}^{-1}$, or purulent respiratory secretion (greater than 25 polymorphonuclear cells per low-power microscopic field (LPF)). Usual exclusion criteria, such as pregnancy, lactation, severe concomitant disease, allergy, photosensitivity, prior use of antibacterials, need for parenteral antibacterial therapy, and concomitant therapy which may interfere with absorption of sparfloxacin were applied. Age greater than 65 yrs, concomitant bronchopulmonary disease, diabetes, malnutrition, alcohol/drug abuse were not exclusion criteria but such patients were monitored carefully. Patients with human immunodeficiency virus (HIV) infection were not excluded but those with frank acquired immune deficiency syndrome (AIDS) were. Informed consent was obtained for all patients.

\section{Study conduct}

Patients were treated on either an in-patient or outpatient basis at the discretion of the individual investigator. They were seen on entry, on day 3, after 7-14 days of treatment, and at follow-up at 6 weeks. Treatment commenced as soon as study admission procedures were completed but before the results of culture were available. Acceptable culture material included expectorated sputum (provided that $>25$ neutrophils and $<10$ epithelial cells were found per LPF), material from protected specimen brush bronchoscopy, material from transtracheal aspiration, pleural fluid and blood. All isolated pathogens (except for intracellular pathogens, such as Legionella pneumophila) were tested for antibacterial susceptibility using MIC microdilution methods as well as disk diffusion. Serum samples were obtained and frozen on admission, and both at end of treatment and follow-up, for serological testing for $L$. pneumophila, Mycoplasma pneumoniae, Chlamydia spp., and Coxiella burnetii. All 
serological tests were performed in the same, centralized reference laboratory (Harrison JG, Public Health Laboratory Services, London, UK). Plasma and urine were also obtained for countercurrent immunoelectrophoresis for pneumococcal antigen. Only pathogens considered usual in culture of respiratory tract secretions were considered for microbiological documentation of the study (S. pneumoniae, Haemophilus influenzae, Moraxella catarrhalis, Escherichia coli, Klebsiella pneumoniae and other Enterobacteriaceae, beta-haemolytic streptococci, coagulase positive Staphylococcus aureus). They were classified, using strict criteria, as pathogen, presumed pathogen, or no pathogen, based on the results of quantitative culture. A documentation by blood culture always indicated a pathogen. The documentation of S. pneumoniae antigen in serum and/or urine designated its classification as presumed pathogen, or pathogen if it was associated with $S$. pneumoniae documented by culture. The infection was considered documented for atypical pathogens in the case of a fourfold rise of antibody titres (to a value $\geq 64$ in the case of $L$. pneumophila) or a single titre $\geq 8$ for immunoglobulin M (IgM) M. pneumoniae specific immunofluorescent antibodies; single titres $\geq 128$ for L. pneumophila and $\geq 64$ in immunoglobulin $\mathrm{G}(\mathrm{IgG})$ M. pneumoniae specific immunofluorescent antibodies were also accepted as documentation of the infection.

A complete medical history and physical examination including vital signs were performed upon admission, and the physical examination was repeated on day 3 , at end of treatment and at follow-up. In addition, temperature was recorded twice daily in hopitalized patients. Symptoms and signs (including chills, chest pain, dyspnoea, cough, sputum quality and others) were recorded at each visit. Laboratory testing was performed at admission and end of treatment and included haematology, serum biochemistry and urinalysis. Patients with significant abnormalities at end of treatment had repeat testing at follow-up. A chest radiograph was performed at inclusion and at follow-up and an additional film could be taken at end of treatment if considered necessary by the investigator.

Adverse events, whether volunteered by the patient or elicited by the investigator by nonspecific questioning, were recorded at each visit after starting therapy and were classified by the investigator with respect to severity and relationship to study medication. A patient could be withdrawn from the study at any time at his or her discretion or could be discontinued by the investigator for medical (e.g. treatment failure or adverse experience) or administrative (e.g. protocol violation) reasons. If possible, a final physical examination, evaluation of signs and symptoms, chest radiograph, culture(s), laboratory tests and sample for sparfloxacin assay were performed prior to withdrawal, and all patients discontinuing therapy were included in the follow-up visit.

\section{Analysis}

All efficacy analyses were performed both for the intention to treat (ITT) population and the population of evaluable patients, and for the time intervals from admission to end of treatment and from admission to follow-up. The principal analysis concerned the population of evaluable patients; the aim of the analysis in the ITT population was to confirm the results of the principal analysis, and to rule out potential bias. The ITT population was defined by those patients randomized and having taken at least one dose of study drug. This population was also evaluated for the clinical safety analysis. Evaluable patients needed to meet entry criteria (i.e. to present a temperature equal or greater than $38^{\circ} \mathrm{C}$ at inclusion, and the presence of a pulmonary infiltrate on admission chest radiograph), to have no associated pathology, such as pulmonary embolism, bronchial cancer, acute pulmonary oedema or ongoing tuberculosis, to have at least 2 days of therapy if failure and 5 days if success. In addition, they must not have received another antibiotic within $24 \mathrm{~h}$ before the first dose of study medication unless taken only on that day, not have been hospitalized for at least 3 days preceding the first dose of study medication, not have used any concomitant prohibited medication (except antibiotics in case of failure), and have no missing data for specific evaluations unless available data clearly indicated failure.

The primary criterion of efficacy was expressed in binary fashion and was an overall success or failure; this criterion integrated both clinical and radiological responses, using automatic, predefined rules of classification. An overall success was defined as any patient with clinical cure and resolution or improvement on chest radiography, or any patient with clinical improvement and resolution on chest radiography. Patients with conflicting clinical/radiological data at end of treatment visit were defined according to the outcome at follow-up; those with conflicting data at follow-up were classified following individual and blind review by an expert committee. Clinical and radiological responses were assessed independently, with clinical response classified as cure, improvement or failure depending on the degree of change in symptoms and signs from baseline, and temperature plus the presence of an underlying chronic cardiorespiratory disease. Radiological response was classified as disappearance, improvement, no change, or worsening.

The classification of the outcome for the nonevaluable patients in the ITT analysis was performed according to the following conventions: totally missing data (loss to follow-up) and a duration of treatment of less than 5 days due to the occurrence of an adverse experience led to a classification as nonsuccess; in the case of partially missing data, and other protocol violations, the classification depended on the individual data according to the expert committee's decision.

Safety analyses included all 808 patients (although data were not available for all patients at all time-points) and were based on adverse events reported, physical findings occurring after treatment was started, changes in vital signs from baseline to end of treatment and follow-up (except temperature which was analysed as an efficacy variable), and laboratory parameters over the course of the study. The analysis of the individually described 
adverse events used a codification according to the Costart dictionary for the international classification of adverse events.

\section{Statistical methodology}

The statistical analysis plan used was based on a onesided equivalence analysis. The following were calculated: $90 \%$ two-sided confidence intervals (90\% CI) for differences in success rates for overall efficacy for the time intervals from inclusion to end of treatment and from inclusion to follow-up. Alpha risk was set at 5\% and the beta risk at $20 \%$. The clinical significance of the observed difference was determined from the upper limit of the interval, and equivalence was accepted if it did not exceed $10 \%$. The power of the conclusion was calculated. These analyses were performed both on the ITT and evaluable (per protocol) populations at end of treatment and at follow-up. The analysis in the evaluable population was considered as the principal analysis. All other analyses were descriptive.

\section{Results}

\section{Patient population}

Eight hundred and eight patients were enrolled between December 1990 and March 1992 at 124 centres in nine countries: France (34\%), Germany (14\%), Italy
(14\%), UK (14\%) and Belgium, Greece, Israel, the Netherlands and Spain combined (24\%). The distribution of patients by treatment group entered into the various analyses is summarized in table 1 . Patient characteristics on admission were similar in the three treatment groups (table 2).

Cultures and serum antibody assays identified a pathogen in 319 patients, representing $39 \%$ of the overall population of the study, corresponding to 153,79 and 87 patients treated with sparfloxacin, amoxycillin-clavulanate and erythromycin, respectively. The isolation of two or more organisms in an individual patient was infrequent; however, 357 pathogens, corresponding to 170, 90 and 97 infections in the sparfloxacin, amoxycillin-clavulanate and erythromycin groups, were isolated. Blood cultures were positive in 29,8 and 18 patients in these groups, respectively. In the patients with a $S$. pneumoniae infection, $46(27 \%)$ were documented by blood culture; the demographic characteristics, underlying chronic cardiobronchopulmonary diseases and clinical presentation of these patients were not different from the whole population except for the respiratory rate which was slightly higher $\left(23 \pm 5\right.$ breaths $\left.\cdot \mathrm{min}^{-1}\right)$ and the more frequent presence of chest pain (84\%). Bilateral pneumonia and pleural effusion were each present in only $4 \%$ of this population.

Pathogens and presumed pathogens isolated are listed in table 3 and represent the number of documented infections. S. pneumoniae (168 patients), H. influenzae (79) and $M$. pneumoniae (36) were the most frequently isolated

Table 1. - Classification of patients for efficacy and safety analyses

\begin{tabular}{|c|c|c|c|c|}
\hline & SPX & $\mathrm{AMX} / \mathrm{CL}$ & $\mathrm{Er}$ & All \\
\hline Patients entered into study $n$ & 401 & 199 & 208 & 808 \\
\hline Patients evaluable for safety $n$ & 401 & 199 & 208 & 808 \\
\hline Patients evaluable for intention to treat analysis $n$ & 401 & 199 & 208 & 808 \\
\hline Patients not evaluable for efficacy $n$ & 77 & 41 & 46 & 164 \\
\hline Pneumonia not documented & 23 & 15 & 14 & 52 \\
\hline Treatment duration $<2$ days & 9 & 4 & 14 & 27 \\
\hline Previous hospital stay $>3$ days & 12 & 5 & 5 & 22 \\
\hline Antibacterial use before inclusion & 7 & 5 & 4 & 16 \\
\hline Associated pathology & 11 & 4 & 6 & 21 \\
\hline Prohibited concomitant drug & 1 & 1 & 0 & 2 \\
\hline Poor compliance & 13 & 7 & 3 & 23 \\
\hline Death & 1 & 0 & 0 & 1 \\
\hline Patients evaluable for efficacy $\mathrm{n}(\%)$ & $324(81)$ & $158(79)$ & $162(78)$ & $644(80)$ \\
\hline \multicolumn{5}{|l|}{ Patients not evaluable for efficacy at the } \\
\hline end of treatment $n$ & 14 & 6 & 4 & 24 \\
\hline Missing efficacy data & 13 & 4 & 3 & 20 \\
\hline Prohibited medication before visit & 0 & 1 & 0 & 1 \\
\hline Visit out of date & 1 & 1 & 1 & 3 \\
\hline Patients evaluable at the end of treatment $\mathrm{n}(\%)$ & $310(77)$ & $152(76)$ & $158(76)$ & $620(77)$ \\
\hline \multicolumn{5}{|l|}{ Patients not evaluable for efficacy at } \\
\hline follow-up $n$ & 39 & 19 & 30 & 88 \\
\hline Missing efficacy data & 5 & 1 & 0 & 6 \\
\hline Prohibited medication before visit & 8 & 7 & 8 & 23 \\
\hline Visit out of date & 1 & 0 & 1 & 2 \\
\hline Missing visit & 25 & 11 & 21 & 57 \\
\hline Patients evaluable at the follow-up $n$ & $285(71)$ & $138(70)$ & $132(63)$ & $556(69)$ \\
\hline
\end{tabular}

SPX: sparfloxacin; AMX/CL: amoxycillin-clavulanic acid; Er: erythromycin. 
Table 2. - Patient characteristics on admission

\begin{tabular}{|c|c|c|c|}
\hline & $\underset{\mathrm{n}=401}{\mathrm{SPX}}$ & $\begin{array}{c}\mathrm{AMX} / \mathrm{CL} \\
\mathrm{n}=199\end{array}$ & $\underset{n=208}{E r}$ \\
\hline Age* yrs & $56 \pm 1$ & $52 \pm 1$ & $55 \pm 1$ \\
\hline Age $>65$ yrs $\%$ & 43 & 34 & 39 \\
\hline Sex ratio $\mathrm{M} / \mathrm{F} \%$ & $68 / 32$ & $64 / 36$ & $62 / 38$ \\
\hline Blacks/Caucasians \% & $2 / 97$ & $1 / 99$ & $2 / 97$ \\
\hline \multicolumn{4}{|l|}{ Ongoing bronchopulmonary } \\
\hline disease $\%$ & 37 & 30 & 34 \\
\hline Chronic bronchitis \% & 23 & 22 & 25 \\
\hline Asthma \% & 7 & 7 & 5 \\
\hline Smokers $(>10$ pack-yrs $) \%$ & 24 & 22 & 27 \\
\hline Alcoholics $\left(>50 \mathrm{~g} \cdot\right.$ day $\left.^{-1}\right) \%$ & 11 & 8 & 11 \\
\hline Temperature at inclusion* ${ }^{\circ} \mathrm{C}$ & $39.0 \pm 0.04$ & $39.2 \pm 0.06$ & $38.9 \pm 0.05$ \\
\hline Chills \% & 57 & 57 & 59 \\
\hline Respiratory rate* breaths $\cdot \min ^{-1}$ & $21 \pm 0.3$ & $21 \pm 0.4$ & $22 \pm 0.4$ \\
\hline Cough $\%$ & 93 & 94 & 94 \\
\hline Sputum \% & 78 & 81 & 82 \\
\hline Dyspnoea $\%$ & 80 & 73 & 74 \\
\hline Moderate & 35 & 39 & 35 \\
\hline Severe & 6 & 6 & 6 \\
\hline Chest pain \% & 64 & 60 & 66 \\
\hline Unilateral pneumonia $\mathrm{n}(\%)$ & $358(89)$ & $177(89)$ & $185(89)$ \\
\hline Bilateral pneumonia $\mathrm{n}(\%)$ & $42(10)$ & $22(11)$ & $23(11)$ \\
\hline Pleural effusion $\mathrm{n}(\%)$ & $40(10)$ & $24(12)$ & $22(11)$ \\
\hline
\end{tabular}

*: mean \pm SEM. For abbreviations see legend to table 1 .

Table 3. - Pretreatment identification of organisms (pathogens or presumed pathogens) and number of patients with a documented infection

\begin{tabular}{|c|c|c|c|}
\hline Organisms & $\begin{array}{l}\mathrm{SPX} \\
\mathrm{n}=401\end{array}$ & $\begin{array}{l}\mathrm{AMX} / \mathrm{CL} \\
\mathrm{n}=199\end{array}$ & $\underset{n=208}{E r}$ \\
\hline S. pneumoniae $\mathrm{n}(\%)$ & $83(21)$ & $35(18)$ & $50(24)$ \\
\hline Pathogen & 63 & 28 & 42 \\
\hline Presumed pathogen & 20 & 7 & 8 \\
\hline H. influenzae $\mathrm{n}(\%)$ & $33(8)$ & $25(13)$ & $21(10)$ \\
\hline Pathogen & 25 & 20 & 14 \\
\hline Presumed pathogen & 8 & 5 & 7 \\
\hline Atypicals $\mathrm{n}(\%)$ & $25(6.2)$ & $19(9.5)$ & $18(8.7)$ \\
\hline Legionella spp. & 1 & 2 & 7 \\
\hline Mycoplasma pneumoniae & 15 & 13 & 8 \\
\hline Chlamydia psittaci & 7 & 3 & 2 \\
\hline Coxiella burnetii & 2 & 1 & 1 \\
\hline S. aureus $\mathrm{n}(\%)$ & $13(3.2)$ & $3(1.5)$ & $2(0.1)$ \\
\hline Pathogen & 9 & 3 & 1 \\
\hline Presumed pathogen & 4 & 0 & 1 \\
\hline M. catarrhalis n (\%) & $6(1.5)$ & $1(0.5)$ & $4(1.9)$ \\
\hline Pathogen & 3 & 0 & 3 \\
\hline Presumed pathogen & 3 & 1 & 1 \\
\hline B-haemolytic streptococci $\mathrm{n}(\%)$ & $3(0.7)$ & $3(1.5)$ & $1(0.5)$ \\
\hline Pathogen & 2 & 1 & 0 \\
\hline Presumed pathogen & 1 & 2 & 1 \\
\hline Enterobacteria n (\%) & $7(1.7)$ & $4(2.0)$ & $1(0.5)$ \\
\hline Pathogen & 6 & 2 & 0 \\
\hline Presumed pathogen & 1 & 2 & 1 \\
\hline $\begin{array}{l}\text { Patients with documented } \\
\text { infection } \mathrm{n}(\%)\end{array}$ & $153(38)$ & $79(40)$ & $87(42)$ \\
\hline $\begin{array}{l}\text { Patients with no documented } \\
\text { infection } \mathrm{n}(\%)\end{array}$ & $248(62)$ & $120(60)$ & $121(58)$ \\
\hline
\end{tabular}

For abbreviations see legend to table 1. 
organisms, followed by $S$. aureus, Chlamydia spp., Enterobacteriaceae, M. catarrhalis, L. pneumophila, $\beta$ haemolytic streptococci and $C$. burnetii, in descending order. Unfortunately, 7 out of the 10 patients with a documented Legionella infection were randomized in the erythromycin group. We assume that this result was an aberration of the randomization because this was a doubleblind, double-dummy study and because the code was not broken in any of these cases. Moreover, the aetiological diagnosis of L. pneumophila was based on the results of serum antibody tests in all cases which usually needs 7-15 days to be obtained, e.g. several days after the antibiotic therapy was initiated.

For $S$. pneumoniae, the MIC90 was $0.5 \mathrm{mg} \cdot \mathrm{L}^{-1}$ for sparfloxacin $\left(0.0007-8 \mathrm{mg} \cdot \mathrm{L}^{-1}\right), 0.12 \mathrm{mg} \cdot \mathrm{L}^{-1}$ for amoxycillinclavulanate $\left(0.06-4 \mathrm{mg} \cdot \mathrm{L}^{-1}\right)$ and $0.25 \mathrm{mg} \cdot \mathrm{L}^{-1}$ for erythromycin $\left(0.015->8 \mathrm{mg} \cdot \mathrm{L}^{-1}\right)$. Eight out of 116 tested strains of $S$. pneumoniae (6.9\%) were less susceptible to penicillin (MIC90 $\geq 0.1 \mathrm{mg} \cdot \mathrm{L}^{-1}$ ), and five other strains (4.3\%) were strictly resistant to penicillin (MIC90 $\geq 1 \mathrm{mg} \cdot \mathrm{L}^{-1}$ ). Five strains $(4.3 \%)$ were resistant to erythromycin.

The most frequent sources for documentation were sputum, blood culture and protected brush bronchoscopy, which documented infection in 145, 57 and 50 cases, respectively, following by soluble antigen for $S$. pneumoniae, transtracheal aspiration, bronchial aspiration and bronchoalveolar lavage.

\section{Efficacy analyses}

The mean duration of treatment was between 9 and 10 days (range 1-16 days) in all three treatment groups. Overall success rates at end of treatment and follow-up both for the population of evaluable patients and the
ITT population are presented in table 4 . They were generally comparable in the three treatment groups, but were always higher for sparfloxacin. In the population of evaluable patients, overall success rates were $87 \%$ for sparfloxacin, $80 \%$ for amoxycillin-clavulanate and $85 \%$ for erythromycin at end of treatment, and the rates declined only slightly at follow-up. Success rates tended to be lower in the ITT population because patients with no available data were automatically classified as failures. Early treatment failures appeared to be slightly more frequent in the amoxycillin-clavulanate group (table 4).

Success rates for $S$. pneumoniae documented infections were similar in the three treatment groups: $85 \%$ for sparfloxacin, $80 \%$ for amoxycillin-clavulanate and $84 \%$ for erythromycin in the evaluable population at the end of treatment, and 82,79 and $80 \%$, respectively, at follow-up in the evaluable population (table 5). Success rates were slightly higher for sparfloxacin than for amoxycillinclavulanate and in $H$. influenzae documented infections (table 5). Overall efficacy rates in infections attributable to other pathogens are summarized in table 5 and show few differences between the three antibacterial regimens, except in the case of disease due to Legionella spp. which did not respond to amoxycillin-clavulanate. There was no difference in overall success rates between patients with and without microbiological documentation of infection at inclusion.

Success rates in patients older than 70 yrs of age were generally consistent with those of the overall population in the sparfloxacin group (78 versus $80 \%$ in the intention to treat population at the end of treatment) but were lower than those of the overall population in the amoxycillinclavulanate group (73 versus $77 \%$ ) and the erythromycin group (65 versus 74\%). There was no consistent correlation between success rate and the presence of a

Table 4. - Overall efficacy in patients at end of treatment and at follow-up on analysis of population of evaluable patients and of intention to treat population

\begin{tabular}{|c|c|c|c|c|c|}
\hline \multirow[b]{2}{*}{ Analyses } & \multirow[b]{2}{*}{ SPX } & \multirow[b]{2}{*}{$\mathrm{AMX} / \mathrm{CL}$} & \multirow[b]{2}{*}{ Er } & \multicolumn{2}{|c|}{$(90 \%$ CI) Power $\%$} \\
\hline & & & & $\mathrm{SPX} v s \mathrm{AMX} / \mathrm{CL}$ & $\mathrm{SPX} v s \mathrm{E}$ \\
\hline Number randomized $\mathrm{n}$ & 401 & 199 & 208 & & \\
\hline $\begin{array}{l}\text { Evaluable population } \\
\text { at end of treatment } n\end{array}$ & 310 & 152 & 158 & & \\
\hline Success $\mathrm{n}(\%)$ & $269(87)$ & $121(80)$ & $135(85)$ & $(-13.4$ to -0.9$)$ & $(-6.9$ to 4.3$)$ \\
\hline Failure n (\%) & $41(13)$ & $31(20)$ & $23(15)$ & $84 \%$ & $90 \%$ \\
\hline Early failure $\mathrm{n}(\%)$ & $11(4)$ & $11(7)$ & $4(3)$ & & \\
\hline $\begin{array}{l}\text { Evaluable population } \\
\text { at follow-up } \mathbf{n}\end{array}$ & 285 & 139 & 132 & & \\
\hline Success n $(\%)$ & $239(84)$ & $104(75)$ & $109(83)$ & $(-16.0$ to -2.0$)$ & $(-7.8$ to 5.2$)$ \\
\hline Failure $\mathrm{n}(\%)$ & $46(16)$ & $35(25)$ & $23(17)$ & $76 \%$ & $81 \%$ \\
\hline $\begin{array}{l}\text { ITT population at end } \\
\text { of treatment } n\end{array}$ & 401 & 199 & 208 & & \\
\hline Success $\mathrm{n}(\%)$ & $324(81)$ & $154(77)$ & $154(74)$ & $(-9.3$ to 2.4$)$ & $(-12.7$ to -0.8$)$ \\
\hline Failure n (\%) & 77 (19) & $45(23)$ & $54(26)$ & $87 \%$ & $87 \%$ \\
\hline Early failure & $11(3)$ & $12(6)$ & $4(2)$ & & \\
\hline $\begin{array}{l}\text { ITT population at } \\
\text { follow-up } n\end{array}$ & 401 & 199 & 208 & & \\
\hline Success n (\%) & $283(71)$ & $130(65)$ & $129(62)$ & $(-11.9$ to 1.4$)$ & $(-15.2$ to -1.9$)$ \\
\hline Failure n (\%) & $118(29)$ & $69(35)$ & $79(38)$ & $79 \%$ & $79 \%$ \\
\hline
\end{tabular}

ITT: intention to treat; $90 \%$ CI: 90\% confidence interval. For further abbreviations see legend to table 1. 
Table 5. - Overall efficacy in evaluable population with microbiological documentation

\begin{tabular}{|c|c|c|c|}
\hline Organism & SPX & $\mathrm{AMX} / \mathrm{CL}$ & $\mathrm{Er}$ \\
\hline \multicolumn{4}{|l|}{ Success rates at end of treatment } \\
\hline S. pneumoniae & $61 / 72(85)$ & $20 / 25(80)$ & $38 / 45(84)$ \\
\hline H. influenzae & $26 / 27(96)$ & $19 / 21(90)$ & $13 / 14(93)$ \\
\hline M. pneumoniae & $12 / 14$ & $11 / 12$ & $6 / 6$ \\
\hline Chlamydia spp. & $7 / 7$ & $2 / 3$ & $1 / 1$ \\
\hline Legionella spp. & $1 / 1$ & $0 / 2$ & $7 / 7$ \\
\hline C. burnetii & $2 / 2$ & $1 / 1$ & $1 / 1$ \\
\hline S. aureus & $8 / 9$ & $1 / 2$ & $2 / 2$ \\
\hline M. catarrhalis & $6 / 6$ & - & $3 / 3$ \\
\hline$\beta$-haemolytic streptococci & $2 / 2$ & $2 / 3$ & $1 / 1$ \\
\hline Enterobacteriaceae & $5 / 5$ & $2 / 3$ & $0 / 1$ \\
\hline No microbiological documentation & $153 / 179(85)$ & $72 / 90(80)$ & $73 / 87(84)$ \\
\hline \multicolumn{4}{|l|}{ Success rates at follow-up } \\
\hline S. pneumoniae & $54 / 66(82)$ & $19 / 24(79)$ & $28 / 35(80)$ \\
\hline H. influenzae & $23 / 24(96)$ & $16 / 19(84)$ & $11 / 12(92)$ \\
\hline M. pneumoniae & $12 / 14$ & $10 / 12$ & $4 / 4$ \\
\hline Chlamydia spp. & $7 / 7$ & $2 / 3$ & $1 / 1$ \\
\hline Legionella spp. & $1 / 1$ & $0 / 2$ & $6 / 6$ \\
\hline C. burnetii & $2 / 2$ & $1 / 1$ & $1 / 1$ \\
\hline S. aureus & $8 / 9$ & $1 / 2$ & $2 / 2$ \\
\hline M. catarrhalis & $5 / 6$ & - & $2 / 2$ \\
\hline$\beta$-haemolytic streptococci & $2 / 2$ & $1 / 2$ & $1 / 1$ \\
\hline Enterobacteriaceae & $5 / 5$ & $2 / 3$ & $0 / 1$ \\
\hline No microbiological documentation & $133 / 163(82)$ & $61 / 81(75)$ & $61 / 75(81)$ \\
\hline
\end{tabular}

Percentage values are presented in parenthesis. For abbreviations see legend to table 1.

specific cardiopulmonary disease, such as asthma, emphysema, chronic bronchitis or chronic heart failure. Blood culture $S$. pneumoniae documented infections were associated with generally lower success rates in all groups; however, the number of these patients involved was small. Success rates were $72 \%$ (13 out of 18 ), $50 \%$ ( 3 out of 6 ) and $73 \%$ (11 out of 15) in the sparfloxacin, amoxycillinclavulanate and erythromycin-treated groups, respectively, at the end of treatment in the evaluable population.

\section{Analyses of failures}

An individual analysis of the failure cases (267 of the 808 patients included, 33\%) showed that 130 out of 267 were so classified on account of the strict application of the evaluability (loss to follow-up, intercurrent event or associated disorder). These different reasons were equilibrated between the groups, except that 12 patients in the erythromycin group were classified as a failure on account of a premature withdrawal of the study medication because of digestive intolerance.

The remaining 137 patients $(17 \%$ of the patients included) corresponded to a failure according to the predefined rules of classification. Of these $58(7 \%)$ occurred during the first week of treatment, with $22(6 \%)$ in the sparfloxacin-treated patients, $24(12 \%)$ in the amoxycillinclavulanate-treated patients and $12(6 \%)$ in the erythromycin-treated patients. These patients presented at the time of failure with a persistent fever, and a worsening or not improved radiographic image, and required the prescription of a new antibiotic therapy. The initial pathogen in these cases was represented by: $S$. pneumoniae in five patients and $M$. pneumoniae in two patients, out of the 22 sparfloxacin-treated patients; $S$. pneumoniae in four patients, L. pneumophila in two patients and $H$. influenzae, M. catarrhalis, Staphylococcus pyogenes and $S$. aureus in one patient each, out of 24 amoxycillinclavulanate-treated patients; $S$. pneumoniae in four patients and $H$. influenzae in two patients, out of the 12 erythromycin-treated patients. However, none of these patients presented an associated microbiological failure, except in one patient in the erythromycin-treated group (H. influenzae). Patients with a failure occurring after the first week of treatment presented less definite clinical and radiological signs and frequently did not require the prescription of a new antibiotic. The overall number of patients requiring a new antibiotic was 40 in the sparfloxacin-treated group (10\%), 35 in the amoxycillinclavulanate group $(18 \%)$ and 31 in the erythromycin group $(15 \%)$; these cases may represent the true antibiotic failures.

\section{Safety analyses}

The three treatment groups were comparable for the incidence and severity of adverse events. Fifty percent of amoxycillin-clavulanate-treated patients reported 179 adverse events and $54 \%$ of erythromycin-treated patients reported 217 adverse events. Gastrointestinal disturbances were the most frequently reported adverse events but were less common in the sparfloxacin-treated group than in the amoxycillin-clavulanate or erythromycin groups; especially diarrhoea with amoxycillin-clavulanate, and 
Table 6. - Most frequently reported adverse events

\begin{tabular}{lrrrrrrr}
\hline & \multicolumn{2}{c}{$\begin{array}{c}\text { SPX } \\
(\mathrm{n}=401)\end{array}$} & \multicolumn{2}{c}{$\begin{array}{c}\text { AMX/CL } \\
(\mathrm{n}=199)\end{array}$} & \multicolumn{2}{c}{$\begin{array}{c}\text { Er } \\
(\mathrm{n}=208)\end{array}$} \\
& $\mathrm{n}$ & $\%$ & $\mathrm{n}$ & $\%$ & $\mathrm{n}$ & $\%$ \\
\hline Diarrhoea & 12 & 3.0 & & 20 & 10.1 & 10 & 4.8 \\
Vomiting & 11 & 2.7 & 8 & 4.0 & 23 & 11.1 \\
Nausea & 9 & 2.2 & 5 & 2.5 & 17 & 8.2 \\
Abdominal pain & 8 & 2.0 & 4 & 2.0 & 11 & 5.3 \\
Headache & 9 & 2.2 & 5 & 2.5 & 4 & 1.9 \\
Insomnia & 9 & 2.2 & 5 & 2.5 & 4 & 1.9 \\
Rash (all types) & 8 & 2.0 & 6 & 3.0 & 2 & 1.0 \\
Constipation & 8 & 2.0 & 3 & 1.5 & 3 & 1.4 \\
Liver function & 5 & 1.2 & 4 & 2.0 & 4 & 1.9 \\
abnormality & & & & & & & \\
\hline
\end{tabular}

nausea, vomiting and abdominal pain with erythromycin (table 6). The most frequent adverse events with sparfloxacin were diarrhoea, vomiting, nausea, headache, insomnia, rash, abdominal pain and constipation, each occurring in $2-3 \%$ of patients. Photosensitivity was reported in two patients treated with sparfloxacin and presumed phototoxicity (rash on sun-exposed areas) was reported in five additional patients. Discontinuation due to adverse events occurred in $3.5 \%, 2.5 \%$ and $7.7 \%$ of sparfloxacin, amoxycillin-clavulanate and erythromycintreated patients, respectively, and deaths in $4.5 \%, 2.0 \%$ and $4.8 \%$, respectively. The majority of deaths in all three groups were cardiopulmonary in nature and none were attributed to study medication, except through therapeutic failure in some cases.

Vital signs varied considerably in individual patients, but mean values followed similar patterns in all three treatment groups, with decreases in temperature, pulse and respiration rate to normal or near-normal, and little change in blood pressure. Changes in laboratory values were also similar in the three treatment groups. Increases in L-aspartate aminotransferase (ASAT), L-alanine aminotransferase (ALAT) and alkaline phosphatase occurred in five patients treated with sparfloxacin, but were moderate and not accompanied by an increase in total serum bilirubin. Similar changes were at least as frequent in control group patients and one patient receiving erythromycin, an 83 year old female, became icteric following administration of the study drug and died of unknown cause.

\section{Discussion}

The patients included in this study were a population with clinical and radiographic features corresponding to well-documented adult CAP. These features as well as microbiological characteristics are representative of CAP in the population at large. One third of the patients presented with associated bronchopulmonary diseases and almost $40 \%$ of them were more than 65 years old. The microbiological documentation rate (39\% of cases), and type and incidence of pathogens are comparable with previously published clinical and epidemiological data [711]. In this study, S. pneumoniae was the most frequently isolated pathogen (21\% of patients), followed by $H$. influenzae (10\%), and atypical pathogens (8\%), with much lower documentation rates for other pathogens. The strict validity criteria used for respiratory samples affirms a high likelihood of true pathogenicity for the organisms classified as pathogens or presumed pathogens.

The use of automatic predefined classification rules for the assessment of success and failure enabled standardization of assessments which could have been compromised by the scope of this large study. The individual and blind review by the Expert Committee of all cases with contradictory data was also based on the same rules.

The statistical analysis used was based on an equivalence hypothesis and this proved very appropriate to a study of antibiotics in community-acquired pneumonia, where success rates are high.

All the success rates were expressed with a 90\% CI. This interval was calculated from the mean success rates and the sample sizes. In order to conclude equivalence, the upper boundary of the interval was not to exceed $10 \%$. The $90 \%$ CI expresses the $90 \%$ probability that the true difference in efficacy of the two antibiotics is situated within these boundaries. The probability that the efficacy of the comparator is actually greater than the upper limit of the $90 \% \mathrm{CI}$ is thus 5\%. The analytical plan was intended to consider only the upper limit of the confidence interval (one-sided test).

The overall efficacy was equivalent in the three treatment groups. The statistical methodology used in this study makes it possible to conclude unequivocally that the efficacy of sparfloxacin was at least equivalent to that of the comparative antibiotics tested. This conclusion is of practical relevance regarding the selection of an antibiotic for the first line therapy of communityacquired pneumonia; this selection can be difficult, especially in cases of doubt as to the precise bacterial actiology.

The overall efficacy in the evaluable population was always higher at the end of treatment than at follow-up, and this was presumably due to relapse. The success rates observed in the ITT population were generally lower than those observed in the evaluable patients, especially at follow-up. This is because patients with no available data, those with a premature withdrawal of treatment for intercurrent events, treated for less than $48 \mathrm{~h}$ or noncompliant, were classified as failure. However, the success rates 
observed in the different treatment groups at both dates of evaluation were consistent with those observed in evaluable patients, confirming the absence of bias and the validity of the analysis.

"Early failures" (days 3 or 4), defined by the investigators as a persistence or even worsening of the infectious and/or respiratory syndrome, corresponded to situations of therapeutic failure and accounted for $3.2 \%$ of the 808 patients. These failures were less frequent with sparfloxacin $(3.5 \%)$ than with amoxycillin/clavulanic acid (7\%). The rate with erythromycin was $2.5 \%$ which should be weighed against the high level of early discontinuations with this antibiotic due to adverse digestive events (8\%).

Success rates for patients with $S$. pneumoniae infections were similar to overall success rates in all three treatment groups. However, the daily dosage of amoxycillin used in this study was $1,500 \mathrm{mg}$, which was the average dosage used in European countries at the time that the study was initiated (end of 1990). This dosage is considered insufficient in regions where $S$. pneumoniae resistance is a problem, and amoxycillin 3,000 $\mathrm{mg} \cdot \mathrm{day}^{-1}$ has been recommended in France [8]. Overall success rates in $S$. pneumoniae infections confirmed in blood cultures were generally lower than in those documented by other methods, and this presumably reflects more serious and extensive disease in these patients.

Success rates in patients with confirmed $H$. influenzae infections were generally higher for sparfloxacin than for both amoxycillin-clavulanate and erythromycin, which confirms the high antibacterial activity of sparfloxacin against this pathogen [5]. Strict criteria were employed for microbiological documentation in this study and this emphasizes the pathogenicity of $H$. influenzae in respiratory tract infections.

In two patients with L. pneumophila infection treatment with amoxycillin-clavulanate failed, whereas one patient treated with sparfloxacin and seven patients treated with erythromycin were successes. Randomization was not balanced in this small subgroup. The high success rate obtained with amoxycillin-clavulanate in M. pneumoniae infections appears surprising, considering the absence of antibacterial activity of beta-lactam antibodies against this pathogen; however, a successful outcome may reflect a spontaneous, favourable evolution of mild infection.

Frequency of adverse event reporting was high in all three treatment arms. Nevertheless, discontinuation due to poor tolerability was infrequent, occurring in only $3.5,2.5$ and $7.7 \%$ of patients treated with sparfloxacin, amoxycillin-clavulanate and erythromycin, respectively. Death during (or shortly after) the study occurred in 4.5 , 2.0 and $4.8 \%$ of these same respective groups, and most deaths were due to cardiopulmonary causes. These relatively low mortality rates were possibly due (at least in part) to study entry criteria that excluded more severely ill patients who required parenteral therapy. Phototoxicity (definite or presumed) was reported infrequently with sparfloxacin $(1.7 \%)$, but most patients were treated in hospital and were carefully warned to avoid exposure to ultra violet light. An increase in platelet count was noted in all three treatment groups and this finding emphasizes the need to mobilize patients as quickly as possible, as well as to implement other prudent measures to prevent venous thromboembolic disease. Mild hepatic dysfunction was seen in several patients in all three groups, but appeared most frequently and was most serious in the erythromycin-treated group.

In conclusion, this study demonstrated the value of use of an equivalence approach for the evaluation of the efficacy of antibiotic therapy and appears promising for future studies. The automatization of the classification system appeared to produce an objective appreciation of an otherwise complex assessment of efficacy for a medication used in community-acquired pneumonia, but this may need to be validated in other clinical studies of this kind. Sparfloxacin (400 mg on day 1, followed by $200 \mathrm{mg}$ o.d.) was at least as efficacious as amoxycillinclavulanate $(500 / 125 \mathrm{mg}$ t.i.d.) or erythromycin $(1 \mathrm{~g}$ b.i.d.) in the treatment of nonsevere community-acquired pneumonia. Adverse events were neither more frequent nor more serious with this new broad-spectrum antibacterial agent.

\section{References}

1. Chow AW, Hall CB, Klein JO, Kammer RB, Meyer RD, Remington JS. Evaluation of new anti-infective drugs for the treatment of respiratory tract infections. Clin Infect Dis 1992; 15 (Suppl. 1): S62-88.

2. The British Thoracic Society, London. Guidelines for the management of community-acquired pncumonia in adult admitted to hospital. Br J Hosp Med 1993; 49(5): 346-350.

3. Societé du tethologie Infectieuse de Langue Francaise. Les infections des voies respiratoires. Quatrième Conférence de Consensus Thérapeutique Anti-Infectieuse (18 Octobre 1991, Lille). Résumé des recommandations. Pressé Med 1991; 20: 2234-2236.

4. Appelbaum PC. Antimicrobial resistance in Streptococcus pneumoniae: an overview. Clin Infect Dis 1992; 15: 72-83.

5. Chin $\mathrm{NX}, \mathrm{Gu} \mathrm{JW}, \mathrm{Yu} \mathrm{KK}$, Zhang $\mathrm{YX}$, Neu HC. In vitro activity of sparfloxacin. Antimicrob Agents Chemother 1991; 35(3): 567-571.

6. Honeybourne D, Baldwin DR, Wise R, Andrews JM. Distribution of sparfloxacin in the bronchopulmonary sites of infection. 17th International Congress of Chemotherapy, Berlin, 1991; Abstract No. 1924.

7. Woodhead MA, MacFarlane JT, McCracken JS, Rose DH, Finch RG. Prospective study of the aetiology and outcome of pneumonia in the community. Lancet 1987; i: 671-674.

8. Marrie TJ, Durant H, Yates L. Community-acquired pneumonia requiring hospitalisation: 5 year prospective study. Rev Infect Dis 1989; 11: 586-599.

9. La Force F. Antibacterial therapy for lower respiratory tract infections in adults: a review. Clin Infect Dis 1992; 14 (Suppl. 2): S233-237.

10. Harrison B. British Thoracic Society Study: communityacquired pneumonia in adults in British hospitals in 19821983: a survey of aetiology, mortality, prognostic factors and outcome. Q J Med 1987; New Series 62 (239): 195-220.

11. MacFarlane JT, Finch RG, Ward MG, Macrae AD. Hospital study of adult community-acquired pneumonia. Lancet 1983 ii: $255-258$. 